\title{
Project initiation workflow for research involving personal data
}

2020-08-19 Version 2.0

Matt Mahon, Mary Donaldson, Georgina Wardle, Johanna King, Stacey Harper

The workflow below outlines the preferred process for initiating a research project involving personal data. Figure 1 is a summary of the workflow, and figure 2 is a full version with links to relevant resources.

If you need to apply for funding, it is best to do so once the Data Management Plan, Data Protection Impact Assessment and Privacy Notice are in place. Remember that it can take some time to review and amend these documents. The key contacts for the project initiation process are:

Research Information Management team: research-datamanagement@glasgow.ac.uk

Data Protection and Freedom of Information office: dp@gla.ac.uk

Contracts team: https://www.gla.ac.uk/myglasgow/researchsupportoffice/contracts-team

Ethics Committee: https://www.gla.ac.uk/research/strategy/ourpolicies/ethics/

Figure 1: Summary workflow diagram.

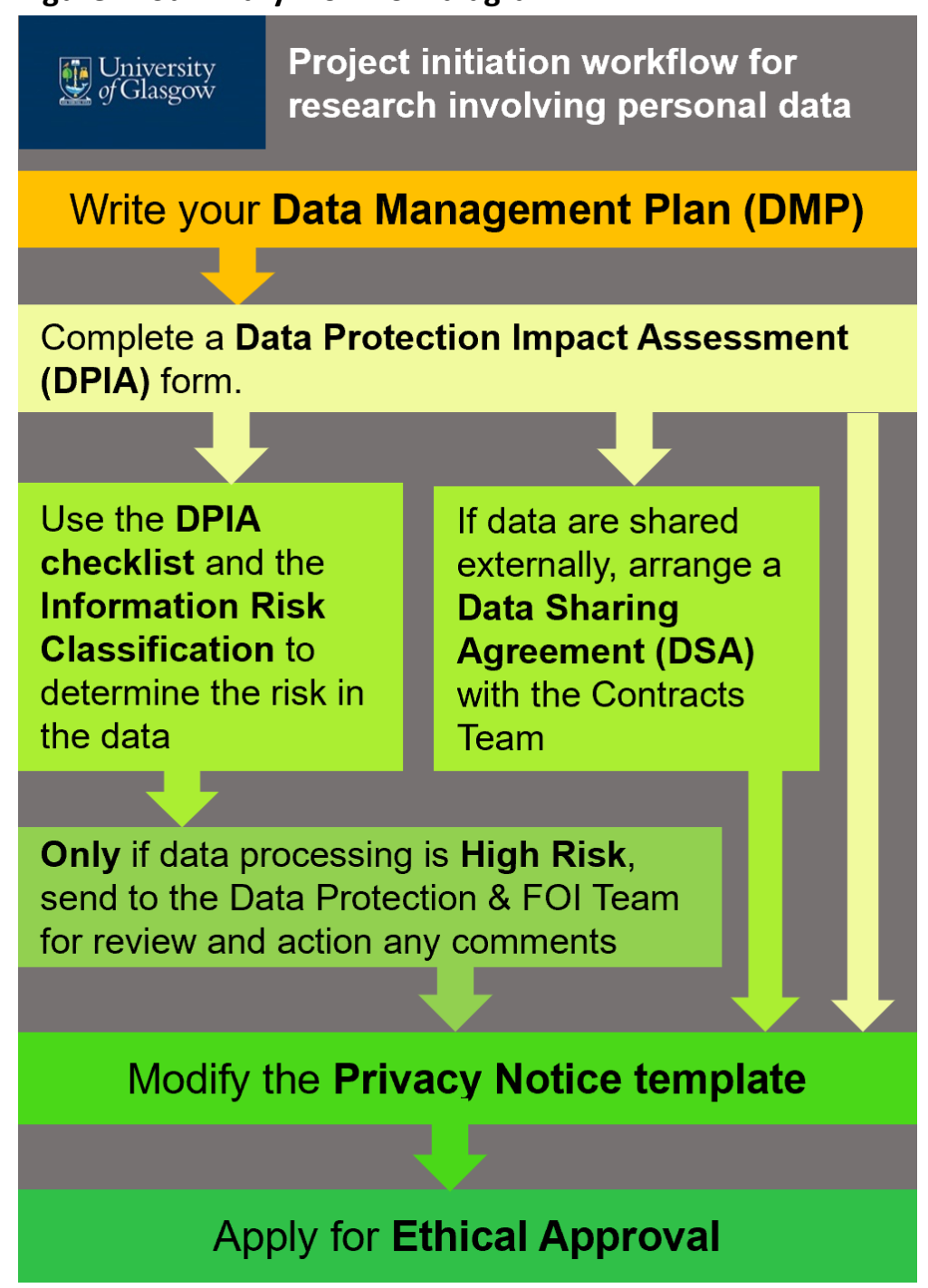


Figure 2: Full workflow diagram.

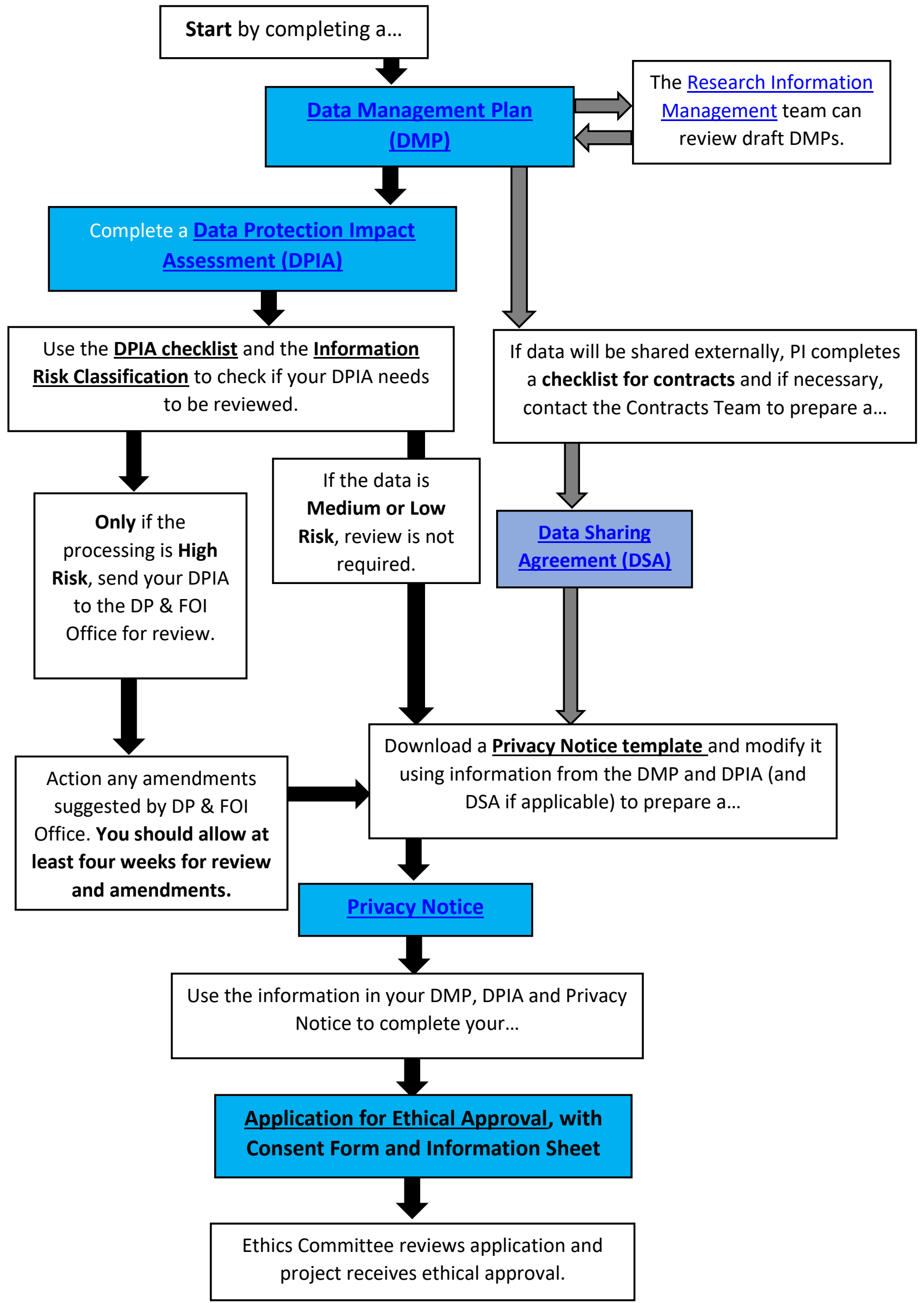

